\title{
Tratado Antártico: 60 años de paz
}

\author{
The Antarctic Treaty: 60th Years of Peace
}

\section{Luis Valentín Ferrada W.}

lvferrada@derecho.uchile.cl

Doctor en Derecho por la Universidad de Chile, profesor del Departamento de Derecho Internacional de la Facultad de Derecho de la Universidad de Chile. Es miembro del Comité Permanente en Humanidades y Ciencias Sociales del Scientific Committee on Antarctic Research (SCAR), en que coordina el Action Group on Resilience and the Future of Science-based Decision-making for Antarctica.

Nuestro gran Pablo Neruda se refiere en 1961 a la Antártica de un modo dialéctico, que continúa interpelándonos en el presente. Es un movimiento en tres tiempos: tesis, antítesis y síntesis. Parte por una afirmación corriente, recurrente, propia de entender el Sexto Continente como una finis terrae, con la carga simbólica de distancia y ajenitud que ello conlleva. Luego la contradice. Finalmente invierte el sentido original y hace aparecer como por arte de magia una verdad nueva y prístina, que da al Continente Austral la preeminencia y valor fundamental que corresponde. Escribe el vate en Las Piedras de Chile que,

$$
\begin{gathered}
\text { "Allí termina todo } \\
\text { y no termina: } \\
\text { allí comienza todo". }
\end{gathered}
$$

La Antártica no es fin, sino punto de partida. Es el último continente al que ha llegado el derecho, pero este, al enfrentar aquella inmensidad austral inmisericorde, enigmática, apabullante, ha debido renacer y reinventarse. El preciso año en que Neruda publicaba estos versos, entraría en vigor el Tratado Antártico, marcando un antes y un después en la historia polar, pero también en la historia del siglo XX y de la paz mundial.

Número de página no utilizable para citar 
Tres años antes, el $1^{\circ}$ de diciembre de 1959, habían concluido las negociaciones respectivas y los representantes de doce países, entre ellos Chile, habían suscrito en la ciudad de Washington D.C. dicho instrumento internacional. Es el año de la Revolución Cubana, y en medio de un mundo polarizado por el enfrentamiento estadounidense-soviético, se pactaba el uso exclusivamente pacífico de la Antártica, su desmilitarización, la prohibición de explosiones nucleares, la libre inspección de todos los sitios e instalaciones y el empleo de la ciencia como mecanismo de cooperación internacional.

Como es obvio, las seis décadas de paz antártica que hoy conmemoramos tienen un antes y un después, y tienen también un futuro hipotético e incierto como todo mañana. El Tratado Antártico, firmado en 1959 y en vigor desde 1961, es el resultado de las anteriores fases de la vinculación del ser humano con el Continente Austral. Este fue anticipado e imaginado al menos desde el siglo $\mathrm{V}$ a.C., considerado por el derecho internacional desde el siglo XV y conscientemente buscado a partir de la centuria siguiente. De Sancho de la Hoz a Pedro de Valdivia, y de este a sus sucesores en el gobierno del Chile colonial, el Polo Sur fue el límite meridional de la capitanía general. Navegando desde Valparaíso, Gabriel de Castilla llegó a las latitudes antárticas en 1603, y a inicios del siglo XIX comenzó la explotación de sus recursos por cazadores de una multiplicidad de naciones. Las Potencias comenzarían a mirar hacia el sur. O’Higgins llamó la atención sobre la condición antártica del Chile independiente en 1831, en 1884 y luego en 1907 se cartografió la Antártica Sudamericana dentro del territorio nacional, en 1892 se reguló la caza de focas y en 1906 nuestro gobierno reivindicó formalmente sus derechos soberanos, delimitados en 1940. Un total de siete estados lo harían durante la primera mitad del siglo XX. Las tensiones del mundo bipolar de la posguerra, así como los conflictos por la superposición de reclamaciones de Chile, Argentina y Reino Unido, convirtieron finalmente a la Antártica en objeto de la preocupación política global. En una iniciativa planificada desde 1955 y concretada en torno al Año Geofísico Internacional 1957-1958, la ciencia fue el instrumento que permitió calmar los ánimos. Su fruto ulterior fue la Conferencia de Washington D.C. de 1959. La paz antártica adquiriría carta de ciudadanía.

Desde entonces, y con mayor precisión jurídica desde 1961, al amparo de las Reuniones Consultivas del Tratado Antártico se desarrollaría un nuevo régimen internacional. Asegurada la paz, pareció imprescindible garantizar la explotación sustentable de sus recursos. La Convención sobre la Conservación de las Focas Antárticas (1972, en vigor 1978) y la Convención sobre la Conservación de los Recursos Vivos Marinos Antárticos (1980, en vigor 1982), son dos de los resultados de esta preocupación. También lo fue, de algún modo, la Convención para la Reglamentación de las Actividades sobre Recursos Minerales Antárticos (1988, no ha entrado en vigor), sin perjuicio que la reacción ante los previsibles efectos ambientales de la explotación de minerales e hidrocarburos abriera el paso hacia la etapa siguiente. Ya no solo era necesario asegurar la paz y el empleo racional y sostenible de los

Número de página no utilizable para citar 
recursos, debía también garantizarse la preservación del medioambiente antártico y sus ecosistemas dependientes y asociados. Así sería consignado en el Protocolo al Tratado Antártico sobre Protección del Medioambiente y sus anexos (1991, en vigor 1998).

Al conmemorarse los 60 años desde la firma del Tratado Antártico pareciera estar consolidada la idea del Sexto Continente como una reserva natural, consagrada a la paz y a la ciencia. Sin perjuicio de ello, su gobierno está colmado de complejidades y es imprescindible enfrentar los desafíos del siglo XXI, tal como el cambio climático o la necesidad de mayores recursos para una población mundial en crecimiento. Prolongar la paz que celebramos es el más deseable de los caminos. 